Article

\title{
Thermomechanical Processing of Cost-Affordable Powder Metallurgy Ti-5Fe Alloys from the Blended Elemental Approach: Microstructure, Tensile Deformation Behavior, and Failure
}

\author{
Carlos Romero ${ }^{1, *(\mathbb{D}}$, Fei Yang ${ }^{1}\left(\mathbb{D}\right.$, Shanghai Wei ${ }^{2}\left(\mathbb{D}\right.$ and Leandro Bolzoni ${ }^{1, *(1)}$ \\ 1 Waikato Centre for Advanced Materials and Manufacturing, School of Engineering, \\ The University of Waikato, Private Bag 3105, Hamilton 3240, New Zealand; fei.yang@waikato.ac.nz \\ 2 Department of Chemical \& Materials Engineering, University of Auckland, Auckland 1142, New Zealand; \\ s.wei@auckland.ac.nz \\ * Correspondence: cr70@students.waikato.ac.nz (C.R.); leandro@waikato.ac.nz (L.B.)
}

Received: 15 September 2020; Accepted: 20 October 2020; Published: 22 October 2020

\begin{abstract}
The development of cost-affordable Ti alloys is key for the application of $\mathrm{Ti}$ in other industries like the automobile sector. Therefore, a combination of powder metallurgy (PM) and low-cost compositions is an interesting approach. In this article, a cost-affordable PM Ti-5Fe alloy is processed following the blended elemental route and extruded at high temperature to remove porosity. Different extrusion temperatures and heat treatments (i.e., solution treatment and aging, STA) are performed to obtain ultrafine microstructures, and their effect on the mechanical behavior is studied. For extrusions in the $\beta$ phase, microstructures consist of coarse lamellar colonies, resulting in alloys with improved properties compared to the as-sintered alloy but still lacking toughness due to the failure happening just after necking onset. Extruding in the $\alpha+\beta$ phase results in a bimodal microstructure of fine elongated primary $\alpha$ and coarse lamellar colonies, and the alloy becomes tougher. STA with aging below the eutectoid temperature of $590{ }^{\circ} \mathrm{C}$ leads to a hard but brittle alloy, whereas STA with aging above it results in alloys with strength comparable to the as-extruded conditions and enhanced ductility.
\end{abstract}

Keywords: titanium alloys; powder metallurgy; thermomechanical processing; mechanical properties

\section{Introduction}

Titanium alloys have an excellent balance of mechanical properties, low density, corrosion resistance, and biocompatibility, which make them highly valuable materials for industries like aerospace, oil and gas, and biomedical. These properties are also attractive for other mass-production sectors like automobile and sporting goods, but the high cost of manufacturing these alloys hinders expanding their applications [1,2]. Powder metallurgy (PM) stands out as one of the main technologies that is used to reduce the cost of Ti alloys. Initially, it was applied as net-shape technology, reducing costs by reducing the amount of machining needed. Recent developments in powder production, starting with the hydride-dehydride (HDH) process [3] and continued with the Metalysis process [4] and others [5], make the PM-blended elemental (BE) approach more cost effective compared to conventional ingot metallurgy. This is because the large amount of melting, forming, and homogenization steps involved in conventional ingot metallurgy are simplified even if PM is not used as a net-shape technology [6].

Alloy design has been determined as another key step to produce cost-effective PM Ti materials [7]. Lower cost alloying elements can be added to simply lower the cost of the alloy, while these alloying 
elements can also help to improve the sinterability of the material, contributing to reduce the processing costs. Typical cost-effective alloying elements that are used in PM Ti are Fe, Mo, and Si. Al can also be considered a cost-effective alloying element, even though it is already extensively used $[7,8]$. Among these, $\mathrm{Fe}$ is the most interesting candidate for the BE approach because it is the cheapest metal in the form of powder, has the highest diffusivity in $\beta$-Ti, and is the strongest $\beta$ stabilizer. The development of PM Ti alloys based on Fe has been gathering attention in the recent years, focusing on the effect of powder characteristics like composition and morphology on the sintering behavior, porosity, microstructure, and properties [9-11]. The high diffusivity of Fe in Ti and the presence of an eutectic phase transformation in the phase diagram at $1090{ }^{\circ} \mathrm{C}$ mean that coarse Fe powder produce large residual pores by the Kirkendall effect and by transient liquid phases. Therefore, the use of fine Fe powder like Fe carbonyl is preferred. Increasing the content of Fe results in an improvement of the sintering behavior, as higher relative densities are obtained after sintering $[9,12]$.

The mechanical properties of Ti-Fe-sintered alloys are typically improved by increasing the amount of Fe not only due to the reduced porosity but also due to microstructural changes and strengthening mechanisms, obtaining optimal properties in the range of 5-7 wt.\% [9]. Additional postprocessing, like HIP or thermomechanical processing removes the effect of porosity. Hence, a trade-off between tensile strength and ductility takes place when the Fe content varies due to microstructural changes and solution strengthening [13]. Another important variable that strongly affects the mechanical behavior is the $\mathrm{O}$ content, as alloys with low oxygen content $(<0.2 \mathrm{wt}$. \%) show a very ductile behavior (elongation to failure above 10\%) [13] compared to alloys with high oxygen content ( $>0.3$ wt. $\%$ ), where the ductility is severely reduced (elongation to failure below 5\%) for similar compositions even after postprocessing $[9,14]$. However, for processing cost-effective Ti alloys, the HDH powders used typically have higher oxygen contents, therefore, their processing needs to be studied carefully to obtain alloys with a good balance of mechanical properties.

The effect of thermomechanical processing on cost-effective PM Ti-Fe alloys has not been evaluated considering different deformation temperature regions as well as heat treatments. In a previous work by the authors [15], the ability to develop ultrafine microstructures using the formation of metastable phases via solution treatment and aging (STA) was studied, finding two regions of interest, one above the eutectoid transformation temperature of $590{ }^{\circ} \mathrm{C}$ and one below. In this work, a combination of extrusions at different temperatures and heat treatments is applied to study the development of microstructures and their effect on the mechanical behavior of a PM Ti-5Fe alloy, in terms of tensile properties, deformation behavior, and tensile failure modes.

\section{Materials and Methods}

HDH Ti powder (Goodfellow Cambridge Ltd., Huntingdon, UK) with particle size of 200 mesh $\left(\mathrm{d}_{90}=75 \mu \mathrm{m}\right)$ and $\mathrm{O}$ content of $0.23 \mathrm{wt} . \%$ was blended with Fe carbonyl powder (Sigma-Aldrich Chemie $\mathrm{GmbH}$, Taufkirchen, Germany) with particle size of 1200 mesh $\left(\mathrm{d}_{90}=10 \mu \mathrm{m}\right)$ and purity of $99.5 \%$ in a 95:5 ratio to obtain a Ti-5Fe composition, using a V-mixer for $60 \mathrm{~min}$ at $60 \mathrm{rpm}$. These blends were compacted in a graphite-lubricated die at $230{ }^{\circ} \mathrm{C}$ using a compacting pressure of $400 \mathrm{MPa}$, reaching a relative green density of $88 \%$ (theoretical density of the blend is $4.60 \mathrm{~g} / \mathrm{cm}^{3}$ ). The billets were sintered at $1300^{\circ} \mathrm{C}$ for $2 \mathrm{~h}$ in high vacuum (around $10^{-2} \mathrm{~Pa}$ ) using a high vacuum furnace $(\mathrm{ZSJ}-20 \times 30$ $\times 30$, Advanced Corporation for Materials \& Equipment Co. Ltd., Changsha, China). The billets were extruded into cylindrical rods at high temperature using a 300-ton horizontal press (Wuxi Yuanchang Machinery Co. Ltd., Wuxi, China) with an extrusion ratio of around 14:1, equivalent to a total plastic deformation of 2.3. The billets were heated in air using a muffle furnace to several temperatures (800, 850 , and $900{ }^{\circ} \mathrm{C}$ ) before the extrusion. STA was applied to the alloys extruded at 800 and $850{ }^{\circ} \mathrm{C}$ via water quenching from 850 and $900{ }^{\circ} \mathrm{C}$, respectively, and two different aging treatments for each alloy, one at $550{ }^{\circ} \mathrm{C}$ (below the eutectoid temperature) and the other at $650{ }^{\circ} \mathrm{C}$ (above the eutectoid temperature). Table 1 shows the oxygen content of powders and of the processed Ti-5Fe alloy in the 
sintered and extruded conditions. This shows that the route followed entailing warm compaction, vacuum sintering, and thermomechanical processing does not result in considerable oxygen pickup.

Table 1. Oxygen Content of the Ti and Fe Starting Powders and of the Sintered and Extruded Powder Metallurgy (PM) Ti-5Fe Alloy.

\begin{tabular}{cccc}
\hline \multirow{2}{*}{ HDH Ti (wt. \%) } & Fe Carbonyl (wt. \%) & \multicolumn{2}{c}{ Ti-5Fe } \\
\cline { 3 - 4 } & & Sintered (wt. \%) & Extruded and Heat-Treated (wt. \%) \\
\hline 0.23 & 0.32 & 0.26 & 0.23 \\
\hline
\end{tabular}

The microstructure of the different alloys was studied using optical microscopy (OM), scanning electron microscopy (SEM), and transmission electron microscopy (TEM). OM was performed using an Olympus BX60 light microscope with a Nikon digital camera (Olympus Corporation, Tokyo, Japan), and SEM observation was done using a Field Emission Hitachi S4700 electron microscope (Hitachi High-Tech Corporation, Tokyo, Japan). The samples were metallographically prepared being ground first with $\mathrm{SiC}$ paper with grit size of 320 grit using water, followed by fine grinding using a diamond suspension and polished with a suspension of colloidal silica. Finally, samples were etched using a Kroll's reagent ( 10 vol. $\% \mathrm{HF}$ and 20 vol. $\% \mathrm{HNO}_{3}$ in $\mathrm{H}_{2} \mathrm{O}$ ). Specimens for TEM were prepared by jet polishing with a $7.5 \mathrm{vol} . \% \mathrm{H}_{2} \mathrm{SO}_{4}$ in $\mathrm{CH}_{4}$ solution under $15 \mathrm{~V}$ in a Struers Tenupol-3. TEM observations were performed on a FEI Tecnai G2 20 microscope (Hillsboro, OR, USA). X-ray diffraction (XRD) measurements were performed on bulk specimens using a PANalytical Empyrean diffractometer (Malvern Panalytical, Malvern, UK) with a $\mathrm{Cu}$ anode and scanning steps of $0.013^{\circ}$. The samples were finely ground before observation using $\mathrm{SiC}$ paper up to grit size of 4000 with water.

The tensile behavior was studied performing uniaxial tensile tests using an Instron 4202 universal testing machine equipped with a static extensometer. Dog-bone specimens with $20 \mathrm{~mm}$ of gauge length and $2 \mathrm{~mm} \times 2 \mathrm{~mm}$ rectangular cross-sections were cut using wire electric discharge machining, along the extrusion direction in the case of extruded alloys, and lightly ground using $\mathrm{SiC}$. The tensile tests were performed by displacement control, at a rate of $0.1 \mathrm{~mm} / \mathrm{min}$. Fractured samples were observed on the SEM and their cross-sections were studied after metallographic preparation.

\section{Results}

\subsection{Microstructures}

The microstructures of the as-processed PM Ti-5Fe alloys are shown in Figure 1. After sintering (Figure 1a), the PM Ti-5Fe alloy has a fully lamellar microstructure and a low amount of porosity (97\% relative density). Pores are closed and spherical, lying within the prior $\beta$ grains, which indicates that the alloy was in the last stage of sintering, where the driving force for grain growth is larger than the pinning effect of pores at the grain boundary, resulting in considerable prior $\beta$ grain coarsening. The prior $\beta$ grain size is of $155 \mu \mathrm{m}$.

After extrusion (Figure $1 \mathrm{~b}-\mathrm{d}$ ), porosity is reduced to a residual amount due to the large deformation applied, obtaining fully dense alloys (relative density of $>99.9 \%$ ). When the extrusion is performed in the $\beta$ phase, at 900 and $850{ }^{\circ} \mathrm{C}$ (Figure $1 b, c$, respectively), the microstructure is fully composed of $\alpha+\beta$ lamellar colonies, and the prior $\beta$ grains have equiaxed morphologies that indicate that the microstructures are formed by dynamic recrystallization (DRX). The prior $\beta$ grain size is much finer after thermomechanical processing, (grain size of $55 \pm 20 \mu \mathrm{m}$ after extrusion at $900{ }^{\circ} \mathrm{C}$, and $45 \pm 13 \mu \mathrm{m}$ after extrusion at $850^{\circ} \mathrm{C}$ ). After extrusion at $800^{\circ} \mathrm{C}$, which is performed in the $\alpha+\beta$ phase, the microstructure is bimodal, composed of a small amount of elongated primary $\alpha$ grains and lamellar colonies (Figure 1d). In these conditions, the resulting volume fraction of primary $\alpha$ is around $3 \%$, and the average thickness is $2.5 \pm 0.8 \mu \mathrm{m}$. When parallel primary $\alpha$ grains are close to each other, the parent $\beta$ grains lying between them have an elongated morphology, with the thickness covering the distance between primary $\alpha$ plates $(\sim 50 \mu \mathrm{m})$ and lengths in the order of the hundreds of micrometer, features 
typical of dynamic recovery (DRV). In areas where the distance between parallel primary $\alpha$ grains is large, the parent $\beta$ grains have an equiaxed morphology and grain size of $\sim 40 \mu \mathrm{m}$, showing signs of DRX.

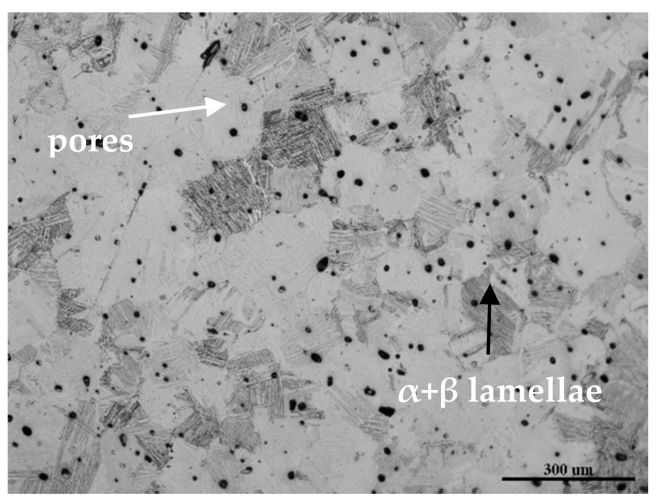

(a)

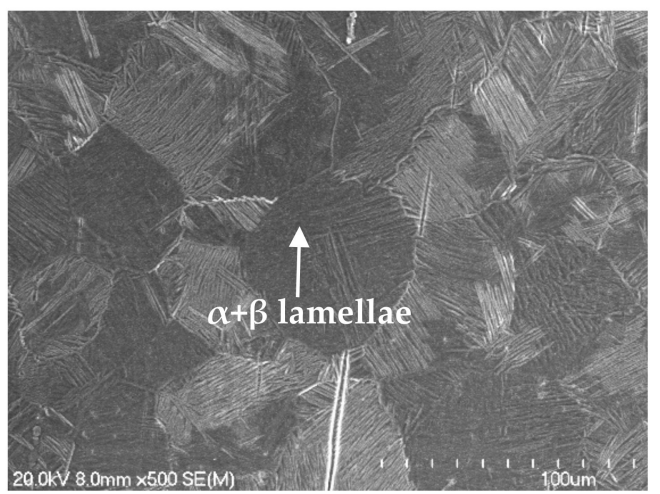

(c)

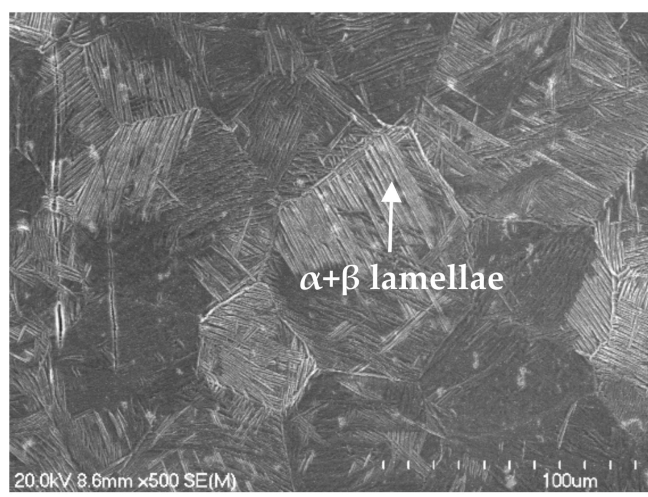

(b)

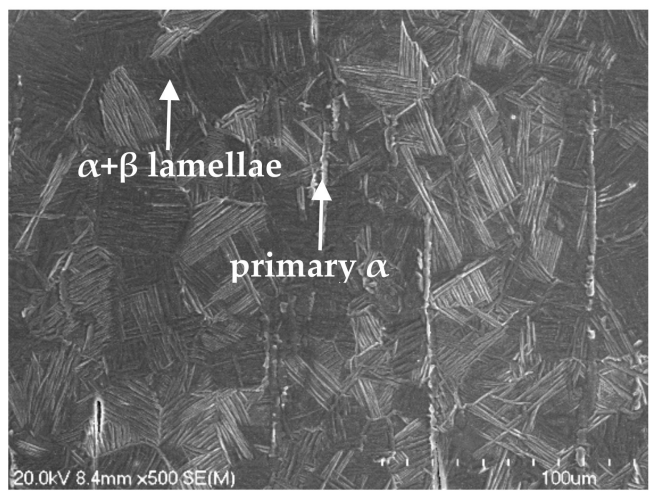

(d)

Figure 1. Microstructures of the powder metallurgy (PM) Ti-5Fe alloys: (a) sintered, (b) extruded at $900{ }^{\circ} \mathrm{C}$, (c) extruded at $850{ }^{\circ} \mathrm{C}$, and (d) extruded at $800^{\circ} \mathrm{C}$.

The XRD patters of the sintered and extruded conditions are shown in Figure 2. It must be noted that the XRD pattern of the extruded alloys is obtained perpendicular to the extruded direction. In the three cases, the present phases are $\alpha$, the most massive, and $\beta$. In the case of the sintered alloy and the alloy extruded in the $\beta$ phase $\left(900^{\circ} \mathrm{C}\right)$, the distribution of relative height of peaks in $\alpha$ is similar, while in the case of $\beta$, the extruded alloy shows preferential orientation for $[100]_{\beta}$ directions perpendicular to the extrusion direction. The diffraction pattern of the alloy extruded in the $\alpha+\beta$ phase $\left(800{ }^{\circ} \mathrm{C}\right)$ has a different distribution of relative height of peaks, showing preferred orientations for [0001] $\alpha$ and $[11-20]_{\alpha}$ directions perpendicular to the extrusion direction.

The evolution of the microstructures during heat treatment of the Ti-5Fe alloy is shown in Figure 3. After water quenching from $900{ }^{\circ} \mathrm{C}$ the microstructure is composed of a retained $\beta$ phase matrix and an ultrafine dispersion of martensitic $\alpha^{\prime}$ with plate width below $100 \mathrm{~nm}$ (Figure 3a). After aging at $550{ }^{\circ} \mathrm{C}$ for $4 \mathrm{~h}$, below the eutectoid temperature, the microstructure is still composed of a $\beta$ matrix (now residual) and very fine $\alpha$ plates, with a width typically between 100 and $200 \mathrm{~nm}$, mostly following a nonlamellar structure (Figure $3 b$ ). The size of $\alpha$ plates becomes considerably larger when the aging is performed above the eutectoid temperature (Figure $3 \mathrm{~d}$ ) compared to that of an aged alloy below the eutectoid temperature (Figure $3 c$ ), and a nonlamellar structure is also formed in this region of the phase diagram. 


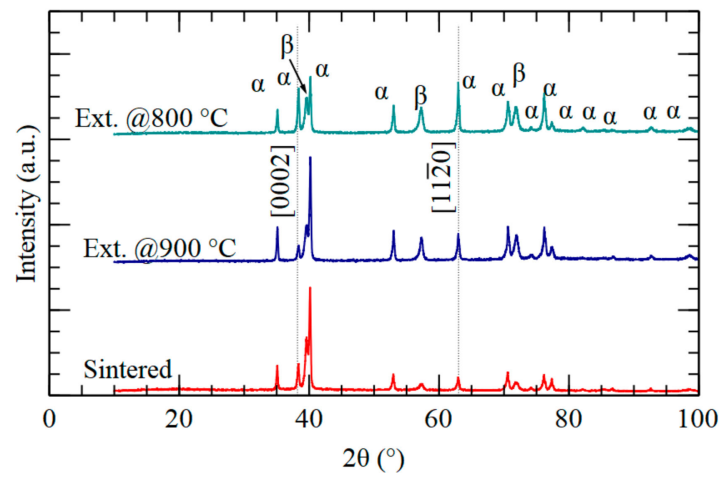

Figure 2. XRD patterns of the sintered and extruded PM Ti-5Fe alloys.

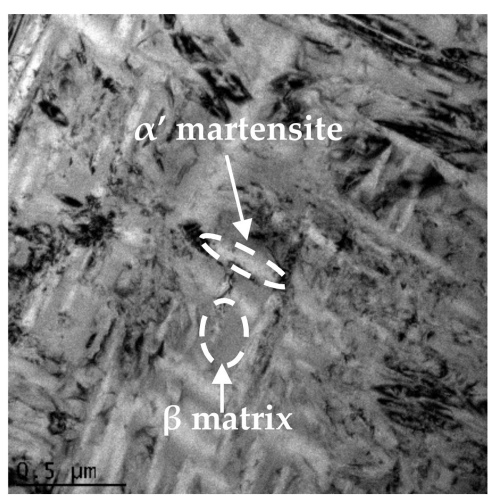

(a)

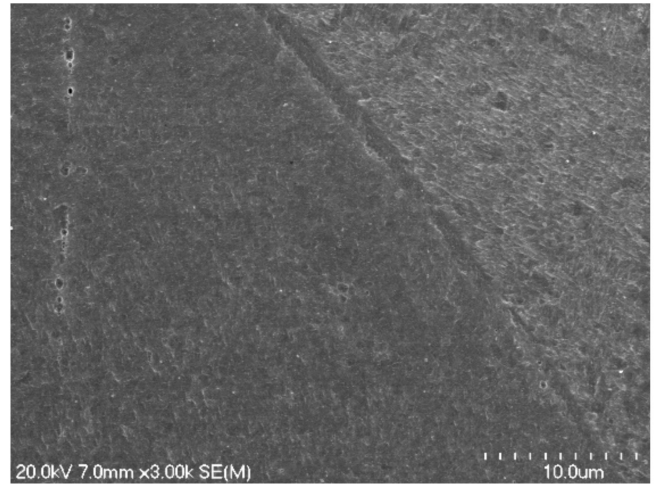

(c)

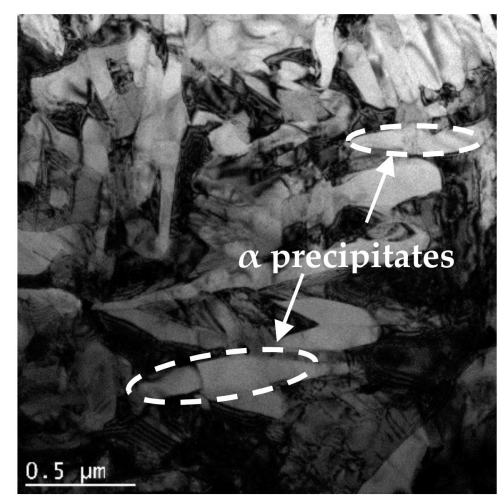

(b)

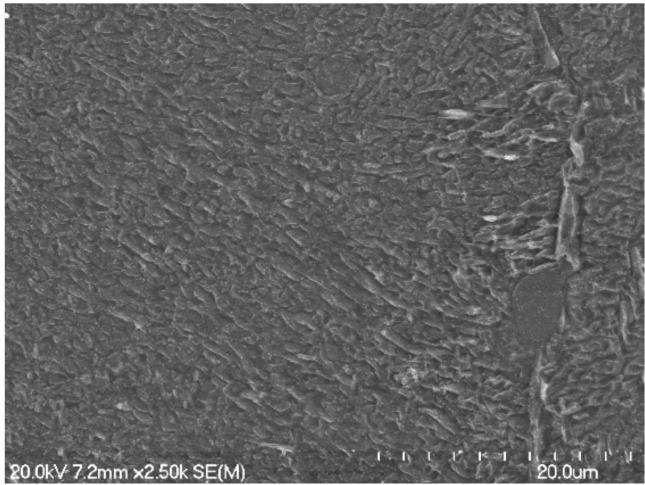

(d)

Figure 3. Microstructures of the extruded and heat-treated PM Ti-5Fe alloy: (a) TEM micrograph of the Ti-5Fe alloy solution treated at $900{ }^{\circ} \mathrm{C}$ and water quenched, (b) TEM micrograph after solution treatment and aging (STA) with aging at $550^{\circ} \mathrm{C}$ for $4 \mathrm{~h}$, (c) SEM micrograph of alloy after STA with aging at $550^{\circ} \mathrm{C}$ for $4 \mathrm{~h}$, and (d) SEM micrograph of alloy after STA with aging at $650{ }^{\circ} \mathrm{C}$ for $4 \mathrm{~h}$.

\subsection{Tensile Behavior: Deformation Behavior and Failure}

\subsubsection{Tensile Deformation Behavior and Properties}

Representative stress-strain curves of the tensile behavior of the Ti-5Fe alloys extruded at different temperatures are shown in Figure 4a, where the curve of the sintered alloy is also included as a reference. There is a considerable increase in the strength and ductility of the alloy after extrusion, regardless of the temperature, compared with the sintered alloy, attributed to the increase in the 
effective load-bearing area and removal of the stress concentration effect that accompanies the reduction in porosity. The extrusions at different temperatures result in alloys with different tensile properties: the alloys extruded in the $\beta$ phase have similar tensile behavior in terms of plastic deformation and total strain at failure, even though the strengths of the alloys are different. The extrusions performed in the $\alpha+\beta$ phase display not only an improvement on the ductility of the alloy compared with the other extrusions but also very different tensile behaviors. The alloy extruded at $800{ }^{\circ} \mathrm{C}$, which has a small amount of primary $\alpha$, has similar stress levels during plastic deformation to those of the alloys extruded in the $\beta$ phase and a similarly small drop of stress after necking.

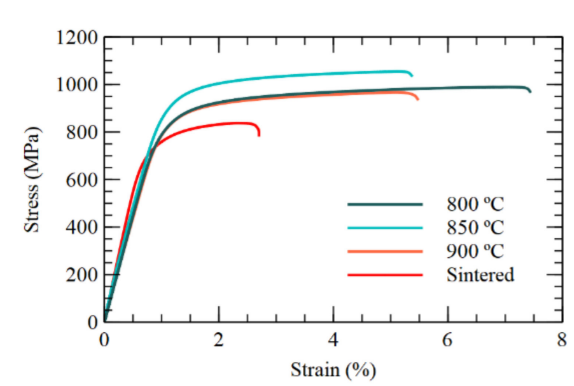

(a)

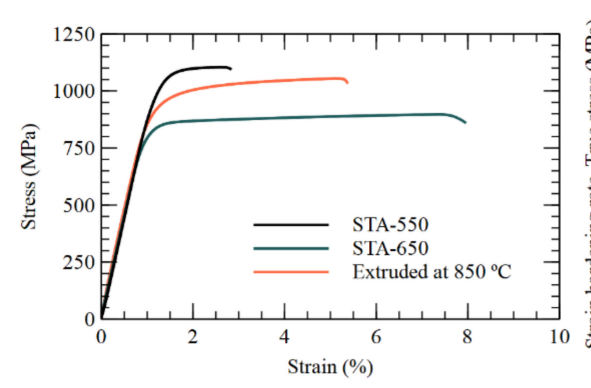

(c)

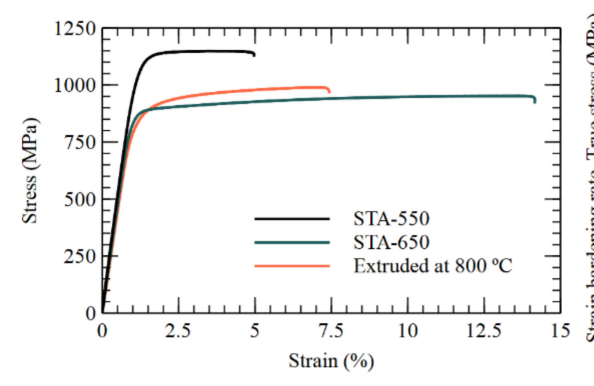

(e)

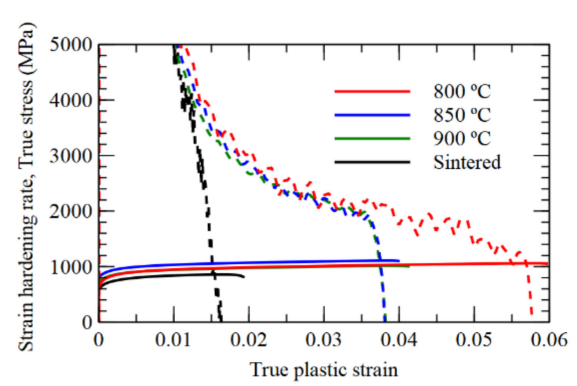

(b)

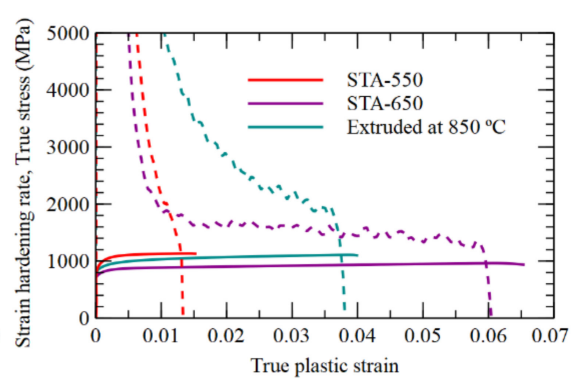

(d)

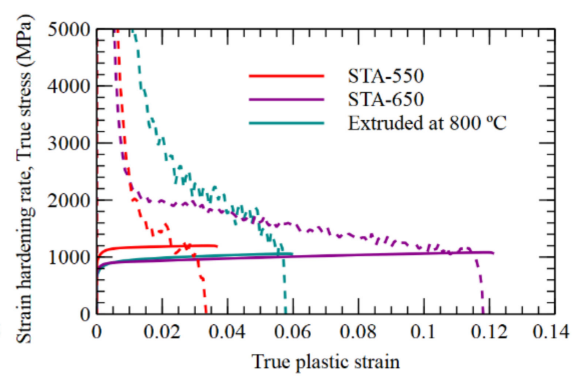

(f)

Figure 4. Tensile behavior of the PM Ti-5Fe alloys under different thermomechanical processing conditions: $(\mathbf{a}, \mathbf{b})$ effect of extrusion temperature, $(\mathbf{c}, \mathbf{d})$ effect of STA on the alloy extruded at $850{ }^{\circ} \mathrm{C}$, and $(\mathbf{e}, \mathbf{f})$ effect of STA on the alloy extruded at $800^{\circ} \mathrm{C}$. $(\mathbf{a}, \mathbf{c}, \mathbf{e})$ stress-strain curves and $(\mathbf{b}, \mathbf{d}, \mathbf{f})$ strain hardening curves.

Figure $4 \mathrm{~b}$ shows the evolution of the strain hardening rates and the true stress with the plastic strain. Following the Considère criterion for necking stability [16], where necking starts at the point where the strain hardening rate is equal to the true stress, the onset of necking happens very close to the point of tensile fracture, showing a limited ability to deform while void nucleation and growth 
takes place. It must be noted that for the alloys extruded in the $\beta$ phase $\left(850\right.$ and $\left.900{ }^{\circ} \mathrm{C}\right)$, there is a sudden drop in the strain hardening rate before crossing the true stress-plastic strain curve, which suggests that necking starts before it is expected, probably due to the presence of defects in the surface of the specimens from machining and grinding.

The tensile behavior of the heat-treated alloys from the extrusion in the $\beta$ phase $\left(850{ }^{\circ} \mathrm{C}\right)$ is shown in Figure 4c, with the as-extruded alloy included as a reference. It can be seen that there is a trade-off between the strength and the ductility of the alloy when heat treated: the alloy aged at $550{ }^{\circ} \mathrm{C}$ has higher strength but lower ductility compared to the as-extruded condition, while the alloy aged at $650{ }^{\circ} \mathrm{C}$ has lower strength but increased elongation. The evolution of the strain hardening rate with the plastic deformation for the three conditions, shown in Figure $4 d$, depicts how in the early stages of deformation, the strain hardening rate of both STA conditions is almost identical and much lower than that of the as-extruded condition until $\varepsilon_{\mathrm{p}} \sim 0.014$, where the STA-550-treated alloy reaches the conditions for necking instability, and the STA-650 has an almost flat strain hardening rate evolution, which surpasses the rate of the as-extruded alloy around $\varepsilon_{\mathrm{p}} \sim 0.04$. The STA-550 alloy also shows a drop in the strain hardening rate before the Considère conditions are met, but in a much lesser scale than that of the as-extruded alloy.

The effect of the different heat treatments on the tensile behavior of the Ti-5Fe alloy extruded in the $\alpha+\beta$ phase (at $800{ }^{\circ} \mathrm{C}$ ) is shown in Figure $4 \mathrm{e}$. As in the case of the extrusion in the $\beta$ phase, the treatment performed below the eutectoid temperature (STA-550) results in a considerable increase in the strength of the alloy, trading off ductility, whereas the treatment above the eutectoid temperature (STA-650) results in a lower strength but increased ductility. The strain hardening behavior (Figure 4f) is similar to the same type of treatment on the alloy extruded at $850{ }^{\circ} \mathrm{C}$. At lower plastic deformation levels, their strain hardening ability is much lower than that of the as-extruded condition, and at plastic deformation levels between $\varepsilon_{\mathrm{p}} \sim 0.005$ and $\varepsilon_{\mathrm{p}} \sim 0.015$, their strain hardening is identical. In the last stage of deformation, however, the STA-550 experiences a sharper decrease in the strain hardening rate, which results in early void nucleation, whereas the STA-650 alloy has a much flatter evolution of the strain hardening rate. This results in the higher ductility as the conditions for void nucleation are not met until $\varepsilon_{\mathrm{p}} \sim 0.115$. It must be noted that in the case of these $\alpha+\beta$-treated alloys, there is no drop in the strain hardening curves.

Tensile properties of the alloys are summarized in Table 2, confirming the trends seen on Figure 4 in terms of strength and ductility. PM Ti-5Fe alloys typically show lower strength and ductility than a PM Ti-6Al-4V alloy processed in similar conditions of pressing, sintering, and extrusion.

Table 2. Tensile Properties of the PM Ti-5Fe Alloys.

\begin{tabular}{ccccccc}
\hline Condition & Heat Treatment & E(GPa) & YS (MPa) & UTS (MPa) & El (\%) & RA (\%) \\
\hline Sintered & - & 105 & 725 & 835 & 2.1 & - \\
\hline Extruded at $900{ }^{\circ} \mathrm{C}$ & - & 87 & 844 & 964 & 4.5 & 10 \\
\hline \multirow{3}{*}{ Extruded at $850{ }^{\circ} \mathrm{C}$} & - & 89 & 900 & 1028 & 3.6 & 15 \\
& $\mathrm{STA}-650$ & 89 & 825 & 896 & 7.0 & 15 \\
\hline & $\mathrm{STA}-550$ & 92 & 1035 & 1110 & 2.0 & 8 \\
\hline \multirow{2}{*}{ Extruded at $800{ }^{\circ} \mathrm{C}$} & - & 88 & 821 & 993 & 6.5 & 15 \\
& $\mathrm{STA}-650$ & 93 & 845 & 948 & 12.5 & 20 \\
\hline Ti-6Al-4V [17] & STA-550 & 96 & 1057 & 1136 & 4.0 & 12 \\
\hline Ti-6Al-4V ASTM B348 & & - & 920 & 1050 & 7 & - \\
\hline
\end{tabular}

\subsubsection{Analysis of Fracture Surfaces}

The fracture surfaces of the as-extruded alloys are shown in Figure 5 . In the case of the alloys processed in the $\beta$ phase (extruded at $900{ }^{\circ} \mathrm{C}$ in Figure $5 \mathrm{a}$ and extruded at $850{ }^{\circ} \mathrm{C}$ in Figure $5 \mathrm{c}$ ), these are composed of elongated dimples, some quasi-brittle features, and a very small quantity of secondary 
cracks. These quasi-brittle features are related to fast void nucleation and growth along colony/colony and prior- $\beta$ grain boundaries, which can be seen in Figure $5 b, d$ as important sources for crack growth. There are no voids or major secondary cracks visible on the neighborhood of the fracture surface (Figure 5b,d), which indicates that the fully lamellar microstructures in Ti-5Fe have a reduced tolerance to tensile damage. This is because, once the damage begins in a localized area by void nucleation, additional deformation is absorbed by void nucleation and growth of the crack front until the final fracture. This results in the lack of postnecking deformation seen in their stress-strain curves in Figure 4 . The fracture surface of the alloy processed in the $\alpha+\beta$ phase (extruded at $800{ }^{\circ} \mathrm{C}$, shown in Figure 5e) is composed of equiaxed and elongated dimples and there are no signs of quasi-brittle features, which are signs of a better ductility. The cross-sectional study in Figure $5 \mathrm{f}$ confirms that the crack does not grow by following boundaries, but rather follows a tortuous path coalescing with voids growing in the neighborhood of the main crack, forming a large proportion of secondary cracks.

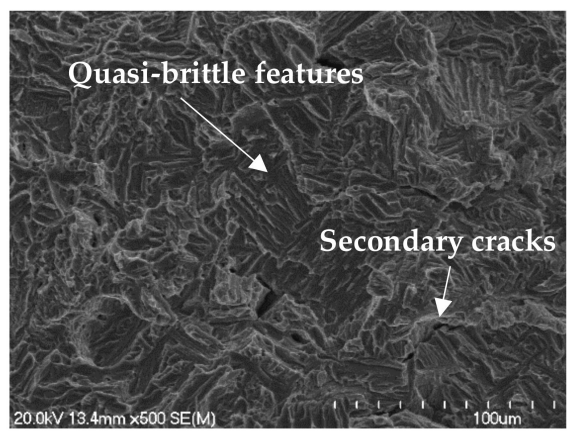

(a)

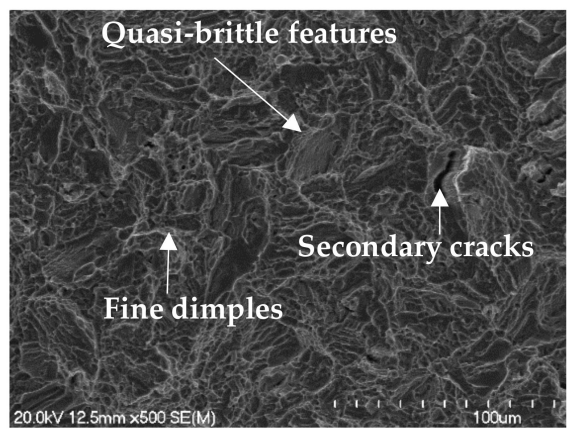

(c)

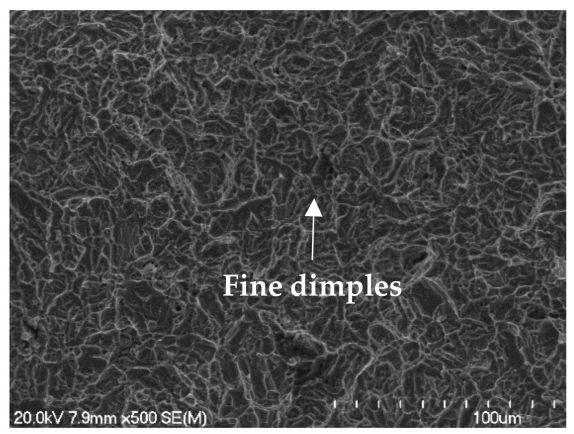

(e)

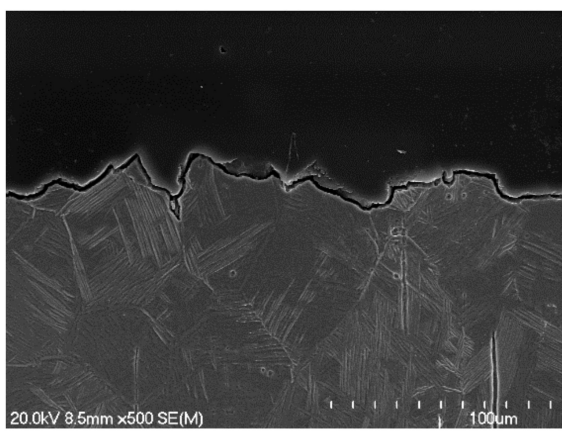

(b)

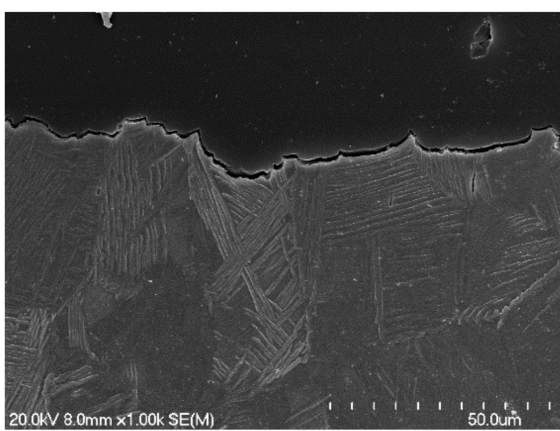

(d)

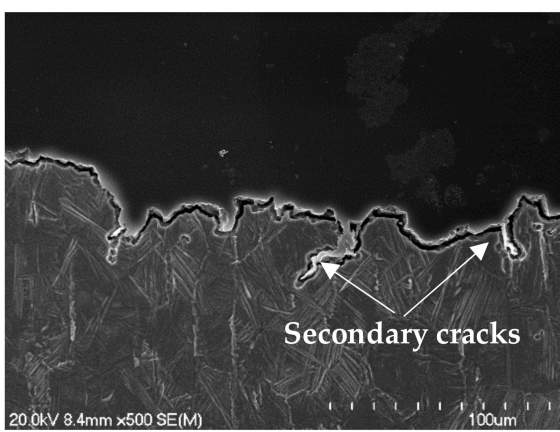

(f)

Figure 5. Fracture surfaces $(\mathbf{a}, \mathbf{c}, \mathbf{e})$ and cross-sections $(\mathbf{b}, \mathbf{d}, \mathbf{f})$ of the PM Ti-5Fe alloys extruded at different temperatures: $(\mathbf{a}, \mathbf{b}) 900^{\circ} \mathrm{C},(\mathbf{c}, \mathbf{d}) 850{ }^{\circ} \mathrm{C}$, and $(\mathbf{e}, \mathbf{f}) 800^{\circ} \mathrm{C}$. 
The fracture surfaces of the heat-treated PM Ti-5Fe alloy extruded at $800{ }^{\circ} \mathrm{C}$ are shown in Figure 6. The STA-550 alloy fails in a brittle manner, in a combination of cleavage along prior $\beta$ grain boundaries and tearing of faces to coalesce the cracks (Figure 5a). Due to the high strength of the ultrafine $\alpha+\beta$ structure formed within the parent $\beta$ grains, the voids nucleate in triple junctions of parent $\beta$ grains and quickly develop cracks along grain boundaries (Figure 5b). There is a moderate number of arrested cracks in the neighborhood of the fractured area, as well as signs of crack deflection, indicating some tolerance to tensile damage even though they form along very weak paths. In the case of the STA-650 alloy, the features of the fracture surface are very fine dimples with the presence of some elongated dimples as well (Figure $5 c$ ). The crack mostly initiates as voids in triple junctions and propagates along the parent $\beta$ grain boundaries (Figure $5 \mathrm{~d}$ ), by void nucleation and growth, not by cleavage. There is a very low number of voids in the neighborhood of the fracture surface, indicating a low tolerance for ductile damage.

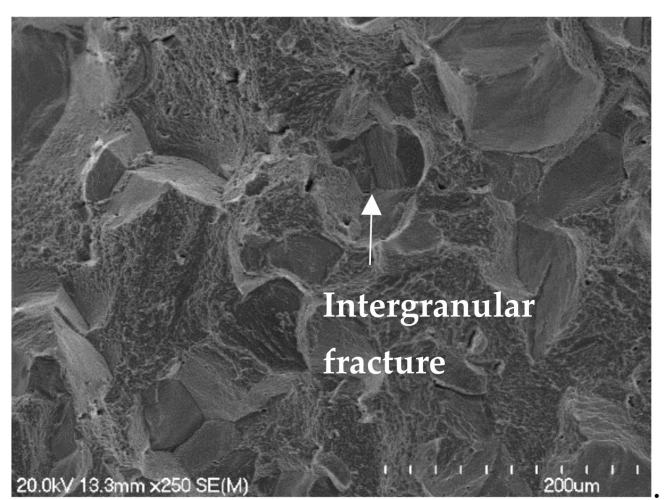

(a)

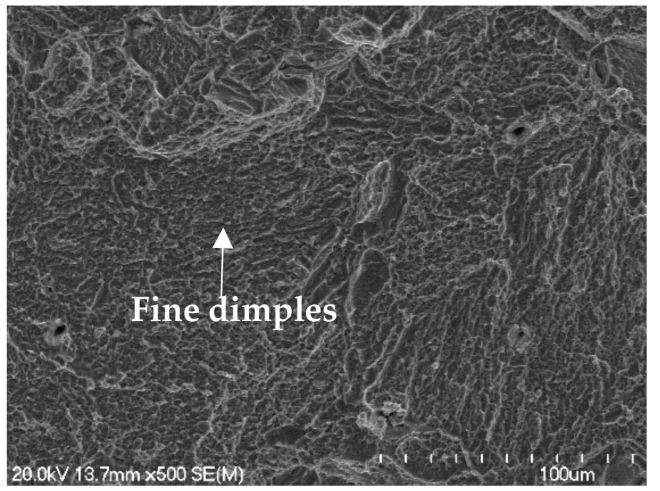

(c)

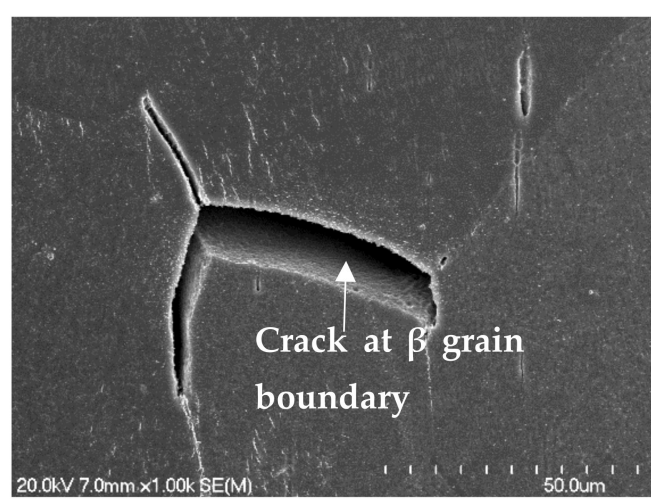

(b)

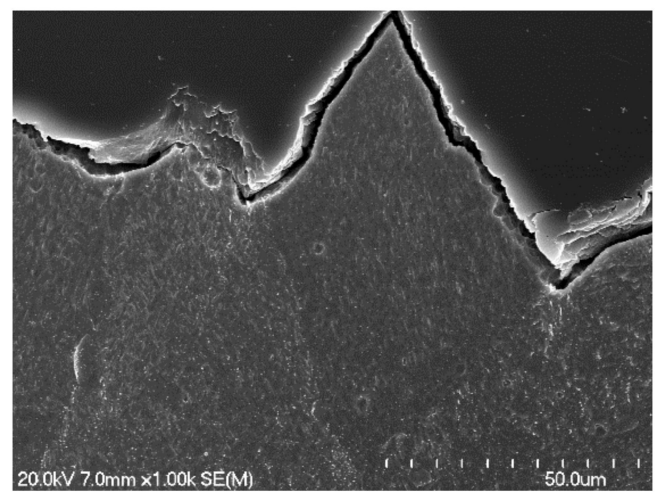

(d)

Figure 6. Fracture surfaces $(\mathbf{a}, \mathbf{c})$ and cross-sections $(\mathbf{b}, \mathbf{d})$ of the heat-treated PM Ti-5Fe alloys extruded at $800{ }^{\circ} \mathrm{C}$ after tensile failure: $(\mathbf{a}, \mathbf{b})$ STA-550 and (c,d) STA-650.

\section{Discussion}

\subsection{Effect of Thermomechanical Processing on the Development of Microstructures of PM Ti-5Fe Alloys}

Thermomechanical processing is a useful approach to remove the porosity of PM Ti alloys because it also provides the means to modify the microstructures and the textures of the alloy. This is compared to HIP, where the microstructures that can be obtained are those derived from fully lamellar microstructures and no texture is developed. In the case of the alloys undergoing DRX, due to the large deformation that the alloy undergoes, a saturation level is reached where all the grains ( $\beta$ phase) 
are recrystallized and therefore have an equiaxed morphology [18]. Therefore, the morphology of the prior $\beta$ grains cannot be modified further unless substantial changes in the deformation rates are applied. This is because the other parameter, temperature, is limited to temperatures above $850{ }^{\circ} \mathrm{C}$. Therefore, as it can be seen from Figure $1 b, c$, the grain size is very similar in this range. Reducing the extrusion temperature to the $\alpha+\beta$ region changes the dynamic mechanisms of $\beta$ to a combination of DRV and DRX, the extent of which is dependent on the amount of primary $\alpha$ present. The size of the lamellar colonies is large in the case of the DRX microstructures, with typically 2-3 colonies formed within each $\beta$ grain. Their size is considerably smaller in the case of DRV grains, with a large number of colonies per $\beta$ grain. There is evidence of strong dependence of the $\beta \rightarrow \alpha$ transformation with the amount of defects generated during deformation at the grain boundaries [19]. It must also be considered that recrystallized grains have no defects or deformation substructures compared with recovered grains, where subgrain structures form within the grain during deformation [20]. This means that the nucleation of $\alpha$ during cooling in DRX grains happens in a homogeneous manner, as there are no preferential points, while in DRV grains, there are many subgrains that will favor heterogeneous nucleation of different $\alpha$ colonies. The refinement of the colony size by promoting DRV over DRX processes in thermomechanical processing in the $\alpha+\beta$ phase is very useful for the improvement of the mechanical properties, as discussed below.

The XRD patterns of the extruded alloys (Figure 2) show preferential orientations in the Ti-5Fe alloy processed in the $\alpha+\beta$ phase, which suggest the formation of transverse texture components (where $[10-10]_{\alpha}$ crystal directions are aligned with the extrusion direction). This is inferred by the simultaneous increase in the intensity of basal and [11-20] $\alpha$ crystal directions perpendicular to the extrusion direction. It would be in agreement with textures observed by EBSD measurements on PM Ti-6Al-4V processed in the $\alpha+\beta$ phase using extrusions with similar profile, deformation degrees, and rates to this PM Ti-5Fe alloy [17]. This is assuming that the difference in composition does not affect dramatically the hot deformation behavior of $\alpha$ and $\beta$ in terms of the relative activity of the different slip systems. This suspected stronger texture component is associated to the presence of primary $\alpha$, which typically deforms developing strong transverse textures in $\alpha+\beta$ titanium alloys [21]. In the case of the alloys extruded in the $\beta$ phase, the degree of texturing is suggested to be low by the similarities between the XRD pattern of the sintered alloy (untextured) and the extruded alloy at $900{ }^{\circ} \mathrm{C}$. Similar extrusions performed in Ti-6Al-4V show that the texture of $\beta$ developed during extrusion has a [101] $\beta$ crystal direction parallel to the extrusion direction, which because of the 12 different variants of the $\beta \rightarrow \alpha$ transformation result in several texture components of $\alpha$ and, in turn, into a weak textured alloy [17].

Another important point to discuss is the importance of the $\beta$ transus in thermomechanical processing of PM Ti alloys. Performing thermomechanical processing in the $\beta$ phase or in the $\alpha+\beta$ phase results in different deformation mechanisms, microstructures, and textures, and these affect the mechanical behavior. First, the $\beta$ transus is dependent on the composition, i.e., pure Ti has the $\beta$ transus at $882{ }^{\circ} \mathrm{C}$, but with an addition of $5 \mathrm{wt} . \% \mathrm{Fe}$, the $\beta$ transus reduces to around $800{ }^{\circ} \mathrm{C}[22]$. However, the strong $\alpha$-stabilizing effect of $\mathrm{O}$ results in a large increase of the $\beta$ transus when the $\mathrm{O}$ content is increased, which is typical of PM Ti alloys. In the case of Ti-5Fe, the $800{ }^{\circ} \mathrm{C}$ in a low $\mathrm{O}$ content (below $0.2 \mathrm{wt}$ \%) alloy of Reference [22] increases to above $900{ }^{\circ} \mathrm{C}$ when the $\mathrm{O}$ content is of 0.46 wt.\% [15]. In the case of the PM Ti-5Fe alloy of this work, the $\beta$ transus is above $850{ }^{\circ} \mathrm{C}$ and below $900{ }^{\circ} \mathrm{C}$, from inspection of microstructures. The other important factor that must be taken into consideration is deformation heating, where the instantaneous temperature of the material is increased due to deformation that is considerably high when the strain rate is large [23], which is the case of the extrusions performed in this work. Because of this deformation heating, during extrusion at $850{ }^{\circ} \mathrm{C}$, which would be performed in the $\alpha+\beta$ phase, the alloy is heated up to above the $\beta$ transus, resulting in a fully lamellar microstructure. Moreover, in the case of the alloy extruded at $800{ }^{\circ} \mathrm{C}$, the amount of primary $\alpha$ is much lower due to the deformation heating than what would correspond to a microstructure processed $50{ }^{\circ} \mathrm{C}$ below the $\beta$ transus. 


\subsection{Solution Treatment and Aging of the PM Ti-5Fe Alloys}

The TEM micrographs of Figure 3a show how after water quenching from the $\beta$ phase, a large portion of the $\beta$ phase is retained and a considerable fraction of $\alpha^{\prime}$ is formed by martensitic transformation. There are no signs of athermal $\omega$ phase formed as a result of quenching. This means that the PM Ti-5Fe alloy is close to being fully metastable. Using the molecular orbital parameters of the alloying elements, the bond order (Bo), and the d-orbital energy (Md), a phase stability map can be plotted that identifies the phase composition of the alloy upon quenching, as well as elastic properties of the Ti alloy [24]. The electronic parameters of $\mathrm{Ti}$ and Fe are tabulated in [25], and the average values of these parameters for the alloy composition are 2.78 and 2.38 for Bo and $\mathrm{Md}$, respectively. With these parameters, the alloy sits very close to the composition where the martensite start temperature is below room temperature, according to the diagrams of Refs. $[25,26]$. The higher O content is expected to modify the values of the average electronic parameters, displacing the alloy in the diagram to the $\beta+\alpha^{\prime}$ region, which correlates well with the TEM results. Therefore, in order to obtain fully metastable $\beta$ Ti-xFe alloys from PM, $x$ should be increased to at least $6 \mathrm{wt} . \%$.

During aging, several decomposition and nucleation transformations take place depending on the range of temperatures applied [15]. Below the eutectoid temperature $\left(590^{\circ} \mathrm{C}\right)$, the formation of very fine phases is assisted by the nucleation and decomposition of the isothermal $\omega$ phase, but the transformation that dominates the formation of the microstructure depends on the temperature. In the case of the aging at $550{ }^{\circ} \mathrm{C}$ during $4 \mathrm{~h}$, the formation of the microstructure is dominated by the growth of $\alpha$ laths through the sluggish consumption of $\beta$ [15], which results in the very fine nonlamellar microstructures of Figure $3 b$,c. Increasing the aging temperature to above the eutectoid transformation temperature, like the case of the aging at $650{ }^{\circ} \mathrm{C}$ for $4 \mathrm{~h}$, the $\alpha$ lath structure becomes coarser (Figure 3d) due to the control of the growth over nucleation of $\alpha$ at the initial stage of aging, and the microstructure reaches a quasi-equilibrium state quickly as seen by the small differences between the phase composition and hardness between 1 and $24 \mathrm{~h}$ in [15]. This shows the flexibility of this type of alloy to obtain ultrafine or very fine microstructures.

\subsection{Tensile Behavior of the PM Ti-5Fe Alloys}

The PM Ti-5Fe alloys in the extruded conditions do not show considerable differences in the deformation behavior due to the similar type of microstructures, based on $\alpha+\beta$ lamellae. The only remarkable difference is when the alloy is extruded in the $\alpha+\beta$ phase $\left(800{ }^{\circ} \mathrm{C}\right)$, where the small amount of primary $\alpha$, with the suggested strong [10-10] $\alpha / /$ ED texture component, helps to toughen the alloy. Because of it, void nucleation and growth happens where the shape of the strain hardening curves predict, based on the Considère criterion, and not much earlier. However, this toughening does not improve the ability of the alloy to sustain deformation when necking is initiated.

The behavior of STA Ti-5Fe, for both $\beta$ - and $\alpha+\beta$-extrusions, is strongly dependent on the aging parameters, i.e., above the eutectoid temperature, there is a larger amount of $\beta$ and the acicular $\alpha$ becomes coarser. Thus, the alloy has low strength and is very ductile. After aging below $590{ }^{\circ} \mathrm{C}$, there is less $\beta$ and $\alpha$ is ultrafine, making the alloy very hard and brittle. The aging temperature strongly affects the YS and the strain hardening behavior. As commented above, regardless of the aging temperature, the initial stages of plastic deformation are very similar, with a very sharp drop of the strain hardening rate, associated to a quick transition from the first slip events to the activation of several slip systems in most grains. This means that the ratios between critically resolved shear stress (CRSS) of soft systems, like basal or prismatic, and those of hard systems, like $<c+a>$ pyramidal, are similar despite the large difference in CRSS between alloys aged below and above the eutectoid temperature.

Hutchinson and Barnett [27] described the observed yield stress in one system $\left(\tau_{s}\right)$ as the sum of the CRSS of that system in a single crystal $\left(\tau_{c, s}\right)$ plus a contribution term $(\Delta)$ that quantifies the hardening associated to the presence of grain boundaries or other mechanisms (Equation (1)). According to [27], grain refinement has a similar hardening contribution in the different systems, so $\Delta$ can be assumed constant for the different systems (s) in Equation (1). Therefore, the ratio between a hard and a soft 
slip system follows Equation (2). After a treatment that results in considerable hardening like the STA-550, $\Delta$ is very high so the ratio of Equation (2) is reduced, and consequently, the activation of hard slip systems in most grains happens at stress levels slightly higher than those of soft systems, which explains the strain hardening behavior seen in Figure 4d,f for the STA-550 alloy compared with the as-extruded condition.

$$
\begin{gathered}
\tau_{s}=\tau_{c, s}+\Delta \\
\frac{\tau_{\text {pyr }}}{\tau_{\text {bas }}}=\frac{\tau_{c, p y r}+\Delta}{\tau_{c, b a s}+\Delta} .
\end{gathered}
$$

However, for STA where aging is performed above the eutectoid temperature (STA-650), the initial strain hardening behavior is similar to that of the STA-550. This happens even though the microstructure is coarser, resulting in a considerably smaller $\Delta$ than in the previous case and a theoretical larger difference between the CRSS of hard systems and of soft ones. The change in the amount and composition of $\beta$ phase between the two conditions (the STA- 650 alloy presents more $\beta$ phase volume fraction) is the responsible for this behavior. It is noteworthy the fact that the STA-650 alloy, which displays a very fine microstructure compared to that of the as-extruded condition, has yield strength in the same range as of the as-extruded alloy and larger ductility despite the lower work hardening capability. The softening of metastable- $\beta$ Ti alloys when the aging temperature is high (around $650{ }^{\circ} \mathrm{C}$ ) is common even when the microstructures are very fine [28].

In terms of the fracture mechanism, aging below the eutectoid temperature results in very hard $\alpha$ precipitates within the $\beta$ matrix, distributed very homogeneously, and the high stress levels achieved during plastic deformation result in localized damage in the softer $\beta$ grain boundary, which then propagates along the boundary in a brittle manner. The softer features of the alloy aged above the eutectoid temperature, speculatively due to the higher $\beta$ phase content, mean that the difference in hardness between the bulk of the grain and the boundaries is much smaller and there is no damage localization leading to early failure. Therefore, these alloys fail in a ductile manner. These results are consistent with those of other STA $\beta$ Ti alloys in the literature [28]. However, for most $\beta$ Ti alloys (that are not based on an $\beta$-eutectoid element), these transitions are rather smooth in terms of the aging temperature [28,29], while in the case of Ti-5Fe alloy, it is strongly dependent on the aging region due to the presence of the eutectoid transformation.

These PM Ti-5Fe alloys display a very limited ability to deform once necking begins regardless of whether the alloy is ductile or brittle. Tougher Ti alloys like Ti-6Al-4V display a considerable ability to deform past the onset of necking for PM and wrought alloys (e.g., see [30,31]), unless the amount of $\mathrm{O}$ is high enough to embrittle the alloy (see [32], with $\mathrm{O}$ content of $0.34 \mathrm{wt.} \%$ ). The amount of $\mathrm{O}$ in the PM Ti-5Fe alloys of this study (0.26 wt.\%) is higher than the standards for wrought Ti ( $0.20 \mathrm{wt} . \%)$, but low for typical cost-effective BE PM Ti, yet it is enough to embrittle the alloy in terms of postnecking deformation, resulting in low reduction in area (RA) values.

\subsection{Comparison with Other Ti-xFe Alloys}

Table 3 shows a summary of the properties of Ti-xFe alloys with compositions close to that of the PM Ti-5Fe alloy, both wrought and PM, for sake of comparison. The O content of the alloys has also been included, due to its importance in PM Ti alloys. These alloys have $\mathrm{O}$ content considerably lower to that of the $0.26 \mathrm{wt} . \%$ of this work. This results in a trade-off between strength and ductility compared to the alloys from Table 2, due to the strong strengthening effect of $\mathrm{O}$. In the case of Ti-6Al-4V, the critical O level where the alloy displays a transition from high tensile ductility to low tensile ductility is around $0.33 \mathrm{wt} . \%$ [33], which could be lower for Ti-xFe alloys due to the strong $\beta$ stabilizing effect of Fe. 
Table 3. Tensile Properties of Ti-xFe Alloys from the Literature.

\begin{tabular}{cccccc}
\hline Composition & Condition & O Content (wt. \%) & UTS (MPa) & El (\%) & Reference \\
\hline $\begin{array}{c}\text { Ti-4Fe } \\
\text { (wrought) }\end{array}$ & $\beta$ annealed & 0.09 & 610 & 10 & {$[34]$} \\
& A $+\beta$ annealed & 0.09 & 700 & 20 & \\
& STA $500^{\circ} \mathrm{C}$ & 0.09 & 1000 & 10 & \\
Ti-4Fe (PM) & STA $600^{\circ} \mathrm{C}$ & 0.09 & 770 & 21 & \\
Ti-5Fe (PM) & As-HIP & 0.17 & 775 & 17 & {$[13]$} \\
Ti-5Fe (PM) & As-sintered & $0.13-0.18$ & 863 & 17 & \\
Ti-4Fe (PM) & STA 640 ${ }^{\circ} \mathrm{C}$ & - & 700 & 20 & {$[35]$} \\
Ti-6Fe (PM) & STA $640^{\circ} \mathrm{C}$ & - & 1100 & 14 & {$[36]$} \\
\hline
\end{tabular}

\section{Conclusions}

In this article, the application of thermomechanical processing to the PM Ti-5Fe alloys was studied with the aim of processing cost-effective Ti alloys with good tensile properties. The effect of different extrusion temperatures and heat treatments on the microstructure and mechanical behavior was analyzed. The following conclusions can be drawn:

1. Extrusions with a large plastic deformation are able to remove most of the porosity of the sintered alloy. When the extrusion temperature is above the $\beta$ transus of the alloy, the resulting microstructure is fully lamellar, with coarse prior $\beta$ grains due to a complete DRX during deformation. Extrusions below the $\beta$ transus have microstructures composed of fine primary $\alpha$ and lamellar colonies formed within coarse prior $\beta$ grains from a mixture of DRX and DRV.

2. Through metastable transformations product of solution treatment and aging, ultrafine microstructures can be developed in the Ti-5Fe alloy. A considerable amount of $\alpha^{\prime}$ martensite is retained upon water quenching, which with the aid of metastable transformations forms ultrafine $\alpha$ laths within the $\beta$ grains. The range of temperatures is crucial to determine the size and the amount of precipitates due to the presence of the eutectoid transformation.

3. The pore removal effect improves the mechanical behavior of the alloy in terms of strength and ductility. However, due to the composition of the alloy, the ductility is low, as fracture happens very soon after necking begins even for conditions with larger elongation to fracture. The lower toughness of the alloy and the lower texturing of Ti-5Fe alloys processed in the $\beta$ phase result in tensile failure happening earlier than what the deformation behavior predicts for those conditions.

4. The ultrafine microstructures developed by solution treatment and aging result in very different behavior depending on whether the aging treatment is performed above or below the eutectoid transformation temperature of $590^{\circ} \mathrm{C}$. Although the STA treat treatment with aging at $550{ }^{\circ} \mathrm{C}$ results in a very hard but brittle alloy, aging at $650^{\circ} \mathrm{C}$ results in an alloy with similar strength to the as-extruded condition but with a considerable improvement of the ductility.

Author Contributions: Conceptualization, C.R., F.Y., and L.B.; methodology, C.R. and S.W.; investigation, C.R., F.Y., and S.W.; writing - original draft preparation, C.R.; writing—review and editing, L.B.; supervision, L.B. and F.Y.; project administration, L.B.; funding acquisition, L.B. All authors have read and agreed to the published version of the manuscript.

Funding: This research was funded by the Ministry of Business, Innovation and Employment of New Zealand, grant number UOWX1402.

Acknowledgments: The authors would like to acknowledge the support of Elena Gordo from the University Carlos III of Madrid.

Conflicts of Interest: The authors declare no conflict of interest. The funders had no role in the design of the study; in the collection, analyses, or interpretation of data; in the writing of the manuscript; or in the decision to publish the results. 


\section{References}

1. Froes, F.H.; Friedrich, H.; Kiese, J.; Bergoint, D. Titanium in the family automobile: The cost challenge. JOM 2004, 56, 40-44. [CrossRef]

2. Froes, F.H.S.; Gungor, M.N.; Ashraf Imam, M. Cost-affordable titanium: The component fabrication perspective. JOM 2007, 59, 28-31. [CrossRef]

3. Barbis, D.P.; Gasior, R.M.; Walker, G.P.; Capone, J.A.; Schaeffer, T.S. Titanium powders from the hydride-dehydride process. In Titanium Powder Metallurgy: Science, Technology and Applications; Qian, M., Froes, F.H., Eds.; Butterworth-Heinemann: Oxford, UK, 2015; pp. 101-116.

4. Mellor, I.; Grainger, L.; Rao, K.; Deane, J.; Conti, M.; Doughty, G.; Vaughan, D. Titanium powder production via the Metalysis process. In Titanium Powder Metallurgy: Science, Technology and Applications; Qian, M., Froes, F.H., Eds.; Butterworth-Heinemann: Oxford, UK, 2015; pp. 51-67.

5. Withers, J.C. Production of titanium powder. In Titanium Powder Metallurgy: Science, Technology and Applications; Qian, M., Froes, F.H., Eds.; Butterworth-Heinemann: Oxford, UK, 2015; pp. 33-49.

6. Kraft, E.H. Summary of Emerging Titanium Cost Reduction Technologies; United States Department of Energy, Office of Energy Efficiency and Renewable Energy, Oak Ridge National Laboratory, Heavy Vehicle Propulsion Materials Program, EHK Technologies: Vancouver, WA, USA, 2003.

7. Liu, Y.; Chen, L.F.; Tang, H.P.; Liu, C.T.; Liu, B.; Huang, B.Y. Design of powder metallurgy titanium alloys and composites. Mater. Sci. Eng. A 2006, 418, 25-35. [CrossRef]

8. Yang, Y.F.; Luo, S.D.; Schaffer, G.B.; Qian, M. The sintering, sintered microstructure and mechanical properties of Ti-Fe-Si alloys. Metall. Mater. Trans. A 2012, 43, 4896-4906. [CrossRef]

9. Esteban, P.G.; Ruiz-Navas, E.M.; Gordo, E. Influence of Fe content and particle size the on the processing and mechanical properties of low-cost Ti-xFe alloys. Mater. Sci. Eng. A 2010, 527, 5664-5669. [CrossRef]

10. O'Flynn, J.; Corbin, S.F. The influence of iron powder size on pore formation, densification and homogenization during blended elemental sintering of Ti-2.5Fe. J. Alloys Compd. 2015, 618, 437-448. [CrossRef]

11. Esteban, P.G.; Bolzoni, L.; Ruiz-Navas, E.M.; Gordo, E. PM processing and characterisation of Ti-7Fe low cost titanium alloys. Powder Metall. 2011, 54, 242-252. [CrossRef]

12. Bolzoni, L.; Herraiz, E.; Ruiz-Navas, E.M.; Gordo, E. Study of the properties of low-cost powder metallurgy titanium alloys by 430 stainless steel addition. Mater. Des. 2014, 60, 628-636. [CrossRef]

13. Majima, K.; Amafuji, K.; Maeda, S.; Nagai, H.; Shoji, K. Characteristic Properties of Hot Isostatically Pressed Ti-Fe Alloys. J. Jpn. Soc. Powder Powder Metall. 1989, 36, 848-852. [CrossRef]

14. Alshammari, Y.; Raynova, S.; Yang, F.; Bolzoni, L. Effect of particle size and manufacturing technique on the properties of the PM Ti-5Fe alloy. Int. J. Refract. Met. Hard Mater. 2020, 90, 105246. [CrossRef]

15. Romero, C.; Raynova, S.; Yang, F.; Bolzoni, L. Ultrafine microstructures in eutectoid element bearing low-cost Ti-Fe alloys enabled by slow bainite formation. J. Alloys Compd. 2018, 769, 226-232. [CrossRef]

16. Considère, A. Mémoire sur L'emploi du fer et de L'acier dans les Constructions, Annales des Ponts et Chaussées I sem; 1885.

17. Romero, C.; Yang, F.; Zhang, S.; Bolzoni, L. Effect of thermomechanical microstructural modification and resulting crystallographic texture on the crack initiation mechanism and fatigue behaviour of PM Ti-6Al-4V. Mater. Sci. Eng. A 2020, 139836. [CrossRef]

18. Huang, K.; Logé, R.E. A review of dynamic recrystallization phenomena in metallic materials. Mater. Des. 2016, 111, 548-574. [CrossRef]

19. Gey, N.; Humbert, M.; Philippe, M.J.; Combres, Y. Modeling the transformation texture of Ti-64 sheets after rolling in the $\beta$-field. Mater. Sci. Eng. A 1997, 230, 68-74. [CrossRef]

20. Raabe, D. Recovery and Recrystallization: Phenomena, Physics, Models, Simulation. In Physical Metallurgy, 5th ed.; Elsevier: Amsterdam, The Netherlands, 2014; Volume 1, ISBN 9780444537713.

21. Lütjering, G. Influence of processing on microstructure and mechanical properties of $(\alpha+\beta)$ titanium alloys. Mater. Sci. Eng. A 1998, 243, 32-45. [CrossRef]

22. Murray, J.L. The Fe-Ti (Iron-Titanium) system. Bull. Alloy Phase Diagrams 1981, 2, 320-334. [CrossRef]

23. Semiatin, S.L.; Seetharaman, V.; Weiss, I. Flow behavior and globularization kinetics during hot working of Ti-6Al-4V with a colony alpha microstructure. Mater. Sci. Eng. A 1999, 263, 257-271. [CrossRef]

24. Kuroda, D.; Niinomi, M.; Morinaga, M.; Kato, Y.; Yashiro, T. Design and mechanical properties of new $\beta$ type titanium alloys for implant materials. Mater. Sci. Eng. A 1998, 243, 244-249. [CrossRef] 
25. Abdel-Hady, M.; Hinoshita, K.; Morinaga, M. General approach to phase stability and elastic properties of $\beta$-type Ti-alloys using electronic parameters. Scr. Mater. 2006, 55, 477-480. [CrossRef]

26. Brozek, C.; Sun, F.; Vermaut, P.; Millet, Y.; Lenain, A.; Embury, D.; Jacques, P.J.; Prima, F. A $\beta$-titanium alloy with extra high strain-hardening rate: Design and mechanical properties. Scr. Mater. 2016, 114, 60-64. [CrossRef]

27. Hutchinson, W.B.; Barnett, M.R. Effective values of critical resolved shear stress for slip in polycrystalline magnesium and other hcp metals. Scr. Mater. 2010, 63, 737-740. [CrossRef]

28. Shekhar, S.; Sarkar, R.; Kar, S.K.; Bhattacharjee, A. Effect of solution treatment and aging on microstructure and tensile properties of high strength $\beta$ titanium alloy, Ti-5Al-5V-5Mo-3Cr. Mater. Des. 2015, 66, 596-610. [CrossRef]

29. Du, Z.X.; Xiao, S.L.; Shen, Y.P.; Liu, J.S.; Liu, J.; Xu, L.J.; Kong, F.T.; Chen, Y.Y. Effect of hot rolling and heat treatment on microstructure and tensile properties of high strength beta titanium alloy sheets. Mater. Sci. Eng. A 2015, 631, 67-74. [CrossRef]

30. Chong, Y.; Bhattacharjee, T.; Park, M.-H.; Shibata, A.; Tsuji, N. Factors determining room temperature mechanical properties of bimodal microstructures in Ti-6Al-4V alloy. Mater. Sci. Eng. A 2018, 730, $217-222$. [CrossRef]

31. Cao, F.; Ravi Chandran, K.S.; Kumar, P.; Sun, P.; Zak Fang, Z.; Koopman, M. New Powder Metallurgical Approach to Achieve High Fatigue Strength in Ti-6Al-4V Alloy. Metall. Mater. Trans. A 2016, 47, 2335-2345. [CrossRef]

32. Singh, A.P.; Yang, F.; Torrens, R.; Gabbitas, B. Solution treatment of Ti-6Al-4V alloy produced by consolidating blended powder mixture using a powder compact extrusion route. Mater. Sci. Eng. A 2018, 712, 157-165. [CrossRef]

33. Yan, M.; Dargusch, M.S.; Ebel, T.; Qian, M. A transmission electron microscopy and three-dimensional atom probe study of the oxygen-induced fine microstructural features in as-sintered Ti-6Al-4V and their impacts on ductility. Acta Mater. 2014, 68, 196-206. [CrossRef]

34. Moiseev, V.N. Properties and heat treatment of Ti-Fe and Ti-Fe-Al alloys. Met. Sci. Heat Treat. 1969, 11, 335-339. [CrossRef]

35. Chen, B.-Y.; Hwang, K.-S.; Ng, K.-L. Effect of cooling process on the $\alpha$ phase formation and mechanical properties of sintered Ti-Fe alloys. Mater. Sci. Eng. A 2011, 528, 4556-4563. [CrossRef]

36. Majima, K.; Isono, T.; Shoji, K. Effect of $(\alpha+\beta)$-Quenching on the Mechanical Properties of Sintered Ti-Fe Binary Alloys. J. Jpn. Soc. Powder Powder Metall. 1987, 34, 349-354. [CrossRef]

Publisher's Note: MDPI stays neutral with regard to jurisdictional claims in published maps and institutional affiliations.

(C) 2020 by the authors. Licensee MDPI, Basel, Switzerland. This article is an open access article distributed under the terms and conditions of the Creative Commons Attribution (CC BY) license (http://creativecommons.org/licenses/by/4.0/). 